\title{
Influence of Extraction Parameters on the Yield, Phytochemical, TLC-Densitometric Quantification of Quercetin, and LC-MS Profile, and how to Standardize Different Batches for Long Term from Ageratum conyoides L. Leaves
}

\author{
Anita Paulina Tambunan ${ }^{1}$, Anton Bahtiar ${ }^{1 *}$, Raymond Rubianto Tjandrawinata ${ }^{2}$
}

Anita Paulina Tambunan ${ }^{1}$, Anton Bahtiar ${ }^{1 *}$, Raymond Rubianto Tjandrawinata ${ }^{2}$ 'Faculty of Pharmacy, Universitas Indonesia, Depok, INDONESIA.

${ }^{2}$ Dexa Laboratories of Biomolecular Sciences, Dexa Medica, Cikarang INDONESIA.

Correspondence

Anton Bahtiar

Department of Pharmacy, Faculty of Pharmacy, Universitas Indonesia, Kampus Baru UI, Depok, INDONESIA.

Phone no: +62 217864049

E-mail: anton.bahtiar@ui.ac.id

History

- Submission Date: 04-06-2017;

- Review completed: 08-06-2017;

- Accepted Date: 22-08-2017

DOI : 10.5530/pj.2017.6.121

Article Available online http://www.phcogj.com/v9/i6

\section{Copyright}

(c) 2017 Phcog.Net. This is an openaccess article distributed under the terms of the Creative Commons Attribution 4.0 International license.

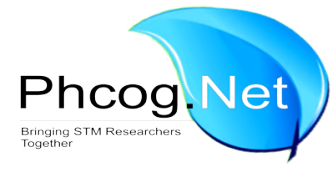

\begin{abstract}
Introduction: Ageratum conyzoides Linn is one of the Indonesian herbs are used as folk medicine. There are many studies to the therapeutic activity. However, the study of the influence in extraction parameters and how to standardize different batches of plant is still limited. Objective: The present study was designed to investigate the influence of extraction parameters on the variables matter, yield, phytochemical profile, and total quercetin from A. conyzoides L. leaves extract. The study also evaluates Liquid Chromatography-Mass Spectroscopy (LC-MS) and TLC fingerprint profiles of the extract to determine the proper quality of plant material of $A$. conyzoides $L$. leaves. Methods: Different temperatures (from $0^{\circ} \mathrm{C}$ to $60^{\circ} \mathrm{C}$ ), solvent types (water and $70 \%$ ethanol (\% v/v), and extraction time (192 h VS $2 \mathrm{~h}$ ) were used to investigate the influence of extraction parameters. The profiles of extract were performed by TLC and LC-MS method. Results: The extract yield was influenced by temperature, solvent types, and time extraction. Our results suggest that the digestion technique at $60^{\circ} \mathrm{C}$ with $70 \%$ ethanol for $2 \mathrm{~h}$ was recommended for the extraction method to obtained high yield and quercetin content as bioactive compound in $A$. conyzoides $L$. leaves extract. The range of quercetin content (40-52 ppm) combined with TLC and LC-MS profile can be used to determine the proper quality of plant material. Conclusion: All parameter of extraction have an affect on the yield extract and total quercetin on the final extract. Thus, there is a need an optimized method to obtain the suitable method.

Key word: Ageratum conyzoides, TLC-Densitometric, Quercetin, LC-MS, Standardization.
\end{abstract}

\section{INTRODUCTION}

Ageratum conyzoides Linn. also known as Bandotan or Babandotan, is one of the Indonesian herbs are used as folk medicine for treating disease include wound dressing, skin diseases, ophthalmic, colic, ulcers treatment, diarrhoea, dysentry, fever, anti-inflammatory, etc. ${ }^{1}$ Many studies have proven the activity of A. conyzoides L. protect against anxyolitic, ${ }^{2}$ pediculosis, ${ }^{3}$ damages generated from arsenic exposure, ${ }^{4}$ etc. The activity of the metabolites in biological conditions might be due to by the presence of secondary metabolites or phytochemical, including alkaloids, flavonoids, chromenes, benzofurans, and terpenoids. ${ }^{5}$ Flavonoids, especially quercetin content is the mostly explored phytochemicals for therapeutic potential in A. conyzoides L. For the example, Awad et al reported that quercetin from the ethyl acetate extract of $A$. conyzoides L. leaves have anti-inflammatory activities against carrageenan induced edema. ${ }^{6}$ Hence, the present study focused into quercetin to evaluate the influence of extraction parameters on the responsible variables extractable matter (yield, extract profile, and quercetin content).
We have known since decades that chemical constituents as extractable matter which obtained from the extraction process were influenced by extraction parameters, also influenced by quality of medicinal plant, including an environmental factors, method of cultivation, time of collection, post-harvest, processing. ${ }^{7}$ Thereby, there is need a tool to evaluation the chemical profile and quantification of bio-active content to standardize different batches of plant material to ensure the reproducibility quality of herbal medicinal product. ${ }^{8}$ Therefore, this study also investigates the chemical profile using TLC and LC-MS method. The extractable matter, TLC $^{9}$ and LC-MS ${ }^{10}$ fingerprint can be used as a reference for standardization of quality of herbal medicines. ${ }^{9,10}$

\section{MATERIALS AND METHODS}

\section{Chemical}

Quercetin (powder) as reference standard was purchased from Sigma-Aldrich (Germany). Water,

Cite this article: Tambunan AP, Bahtiar A, Tjandrawinata RR. Influence of Extraction Parameters on the Yield, Phytochemical, TLC-Densitometric Quantification of Quercetin, and LC-MS Profile, and how to Standardize Different Batches for Long Term from Ageratum conyoides L. Leaves. Pharmacog J. 2017;9(6):767-74. 
methanol, and acetonitrile for chromatograhpy (LC-MS Grade) LiChrosolv ${ }^{\circledast}$ were purchased from Merck (Darmstadt, Germany). All others chemical for analysis, including ethanol, ethyl acetate, toluene, formic acid for analysis (Emsure ${ }^{\oplus}$ Grade) were purchased from Merck (Darmstadt, Germany).

\section{Collection and authentication of plant material}

The plants material of $A$. conyzoides leaves were collected from three different places in Java, among others Indonesian Spice and Medicinal Crops Research Institut (ISMCRI) (West Java), Purwokerto (Central Java), and Materia Medica (East Java). A. conyzoides L. leaves was identified by Indonesian Insitute of Sciences, Research Center for Biology with identification number 1626/IPH.1.01/If.07/VII/2016. The leaves were seperated, washed, dried, milled into powder, and then stored in a closed container for futher use.

\section{Preparation of extracts using maceration technique}

One hundred grams (100 g) of A. conyzoides L. leaves powder was extracted using ethanol $(70 \%, \% \mathrm{v} / \mathrm{v})$ at room temperature for 192 hours. After 192h, the mixtures were filtered with vacuum filtered using Buchner funnel. After that, the filtrate was evaporated at $60^{\circ} \mathrm{C}$ under reduced pressure using Buchi Evaporators R-215 (integrated vacuum controler, water bath, and diagonal V-condenser, Switzerland) to obtain the concentrated extract. Then, the concentrated extract was dried in the oven Memmert. Dried extract stored in the closed glass bottle for futher use, namely crude ethanolic extract. The crude water was prepared by the same method of ethanolic crude extract, but crude water was made in the pure water.

\section{Preparation of extracts using digestion technique}

One hundred grams (100 g) of A. conyzoides L. leaves powder was extracted using ethanol $(70 \%, \% \mathrm{v} / \mathrm{v})$ at $40,50,60$, and $70^{\circ} \mathrm{C}$, respectively for $2 \mathrm{~h}$. After $2 \mathrm{~h}$, the mixtures were filtered with vacuum filtered using Buchner funnel. After that, the filtrate was evaporated at $60^{\circ} \mathrm{C}$ under reduced pressure using Buchi Evaporators R-215 (integrated vacuum controler, water bath, and diagonal V-condenser, Switzerland) to obtain the concentrated extract. Then, the concentrated extract was dried in the oven Memmert. Dried extract stored in the closed glass bottle for futher use, namely crude ethanolic-D extract. The crude water was prepared by the same method of ethanolic crude extract, but crude water was made in the pure water.

\section{Preparation of sample solution}

Each sample of dried A. conyzoides L. leaves extract ( $2 \mathrm{mg}$ ) was dissolved in $70 \%$ ethanol $(1 \mathrm{~mL})$. All solutions were filtered through a $0.45 \mu \mathrm{m}$ nylon membrane filter (Whatman). The sample was filtered before spotting.

\section{Preparation of standard solution}

Quercetin reference standard (Sigma-Aldrich, Germany) was accurately weighed and disolved in $70 \%$ ethanol for the preparation of stock solution (200 ppm). Standard working solution of quercetin was prepared by diluting the stock solution with ethanol $70 \%$ in a $10 \mathrm{~mL}$ volumetric flask to obtain working standard solution at the concentration of $20,40,60$, 80, 100, and 120 ppm.

\section{Thin layer chromatography study for phytochemical profiling}

Each sample solution and standard were spotted by automatic sampler (Automatic TLC Sampler 4, CAMAG) on a 60 F254 silica gel plate (Merck, Germany) and subsequently eluted using solvent system of toluene, ethyl acetate, and formic acid in ratio of 58: 33: $9(\mathrm{v} / \mathrm{v} / \mathrm{v})$ with track distance $0.50 \mathrm{~cm}$ and the migration distance was $90 \mathrm{~mm}$. Detection was done under ultraviolet at 254 and $366 \mathrm{~nm}$ without chemical treatment. In addition, all spots clearly visible at white light and $366 \mathrm{~nm}$ after derivatized with alumunium chloride $\left(\mathrm{AlCl}_{3}\right) 1 \%(\% \mathrm{w} / \mathrm{v}$ in ethanol) and sulphuric acid $\left(\mathrm{H}_{2} \mathrm{SO}_{4}\right) 10 \%(\% \mathrm{v} / \mathrm{v}$ in water). CAMAG TLC Visualizer with winCATS software was used for imaging, analysis, and documentation of TLC.

\section{Thin layer chromatography study for quantification of quercetin}

Each sample solution and all of each standard solution were spotted on a 60 F254 silica gel plate using automatic sampler (Automatic TLC Sampler 4, CAMAG) and subsequently eluted using solvent system of toluene, ethyl acetate, and formic acid (58:33:9) with track distance $0.50 \mathrm{~cm}$ and the migration distance was $90 \mathrm{~mm}$. Detection was done under ultraviolet at 254 and $366 \mathrm{~nm}$ without chemical treatment. In addition, all spots clearly visible at white light and $366 \mathrm{~nm}$ after derivatized with alumunium chloride $\left(\mathrm{AlCl}_{3}\right) 1 \%(\% \mathrm{w} / \mathrm{v}$ in ethanol) and sulphuric acid $\left(\mathrm{H}_{2} \mathrm{SO}_{4}\right) 10 \%(\% \mathrm{v} / \mathrm{v}$ in water). The fluorescence emission of querceti $\left(\mathrm{R}_{\mathrm{F}}=0.51\right)$ was recorded under UV radiation at $366 \mathrm{~nm}$, by means of a digital camera, the images were analysed by CAMAG TLC Scanner 3 with winCATS software. The amounts of quercetin in the samples were calculated by comparing densitogram peak areas from the samples with those from the standards on the same plate at maximum wave length (425 nm). For determination of calibration equations 20, 40, 60, 80, 100, and $120 \mathrm{ppm}$ for quercetin standard were chromatographed.

\section{LC-MS Analysis for secondary phytochemical profiling}

The sample extract $(5 \mathrm{mg}$ ) was dissolved in $1 \mathrm{~mL}$ methanol (LC-MS grade, Chromasolv) and filtered with Whatman membran filters nylon pore size $0.2 \mu \mathrm{m}$ (Sigma-Aldrich). Then, the extract $(5 \mu \mathrm{L})$ was analysed on an UPLC-QtoF-MS/MS System (Waters Corporations, Milford, MA). Sample extract $(5 \mu \mathrm{L})$ was separated on an ACQUITY UPLC BEH C18 Column $(1.7 \mu \mathrm{m} \times 2.1 \mathrm{~mm} \times 50 \mathrm{~mm})$ at $40^{\circ} \mathrm{C}$. A gradient elution method was used with water-formic acid $0.1 \%(\% \mathrm{v} / \mathrm{v})$ as solvent $\mathrm{A}$ and acetonitrile-formic acid $0.1 \%(\% \mathrm{v} / \mathrm{v})$ as solvent $\mathrm{B}$, flowing $0.3 \mathrm{~mL} / \mathrm{min}$. It started with $A: B$ in ratio $95: 5$ for the first minutes, then increased the linearity with solvent B for $6 \mathrm{~min}$, and hold at solvent with A:B in ratio 95:5 from $7.5 \mathrm{~min}$ to $9 \mathrm{~min}$. The total chromatographic run time was $9 \mathrm{~min}$. High definition mass spectrometry was performed on a XEVO-G2-Quadropole (Q)-Time of Flight Mass (ToF) system (Waters, Milford, MA) in V-optics and operated in Electrospray Ionization (ESI) positive (resolution mode) to enable detection of secondary metabolite compounds. The optimal conditions of analysis were as follows: Capillary voltage of $3 \mathrm{kV}$, the sampling cone at $38 \mathrm{~V}$, desolvation temperature at $300^{\circ} \mathrm{C}$, source temperature at $110^{\circ} \mathrm{C}$, flow rate of desolvation gas at 500 liters/ hours, and flow rate of cone gas at 16 liters/ hours.

\section{RESULTS AND DISCUSSION}

\section{The effect of extraction conditions on yield}

There are manys steps to obtain the phytochemicals from plant, such as milling, grinding, homogenization, and extraction. ${ }^{11}$ The extraction process is the important step to minimize interference from compounds that may co-extract with the target compund, so we can obtain the extract with high content of bio-active compund. ${ }^{12}$ It is believed that bioactive compounds from plant foods may have health beneficial effects and reduce the risk of diseases. ${ }^{13}$ This work focused on the discussion of effect of various extraction conditions to the chemical compounds and quercetin content in the extract as extractable matter. The extractable water can be used as indicator to choose the suitable extraction technique. These results are shown in Figure 1.

As shown in Figure 1, the extraction time showing a significant effect on total yield extract from A. conyzoides L. Based on the results, the highest yield extract was obtained using water as solvent. Based on the results, the highest extract yield obtained by crude water extract $(30.20 \% \mathrm{w} / \mathrm{w})$, followed by crude ethanolic extract $(15 \% \mathrm{w} / \mathrm{w})$ when the 
process of extraction using maceration technique for $192 \mathrm{~h}$. These results are in accordance with the expected that a longer extraction time generally led to a higher percentage yield. The longer extraction time values allow for the longer ammount of time the solute and solvent were in contact, so it make the systems have been successfully mass transfer. However, the long of extraction time may cause the additional cost.

As described in Figure 1, heat-extraction methods shown to have advantages of savings in time and energy. As shown in Figure 1, digestion technique at $60{ }^{\circ} \mathrm{C}$ only for $2 \mathrm{~h}$ using water as a solvent can produce the yield exract as much as $14.10 \%(\% \mathrm{w} / \mathrm{w})$. It indicates that the digestion method had a positive effect to reach an optimum yield extract with minimum extraction time.

Figure 1 gives us information about that the aqueous solvent had a positive effect to reach an optimum yield extract. For the example, the extraction yield of water extract from digestion method for $2 \mathrm{~h}$ at $40^{\circ} \mathrm{C}$ is $12.90 \%(\% \mathrm{w} / \mathrm{w})$, while the ethanolic extract only $8.90 \%(\% \mathrm{w} / \mathrm{w})$. This may be attributable to higher solubility of sugars and oligosaccharides in water than ethanol, so the yield of water is higher than ethanol. These results seem to be in line with the effect of various solvent systems on extraction sugar from beach pea (Lathyrus maritimus L.) ${ }^{14}$ and some medicinal plants. ${ }^{15}$

\section{Phytochemical profile of A. conyzoides L. leaves extracted via different extraction methods.}

An extraction technique of medicinal plants contributes significantly to the final quality of the herbal drug. ${ }^{16}$ For the example, temperature's effect on extraction is dual. On one hand, higher heating process can destroy certain chemical compound in the extract and may adversly affect the efficacy of medicinal plants, ${ }^{17}$ thereby there is need a tool to ensure the quality of the extract. In the last 20 years or so, an online chromatographic system has emerged as the most important method for the identification of target and unknown chemical compounds. ${ }^{18}$ Therefore, the present study was used TLC to evaluate the chromatographic pattern of the A. conyzoides L. leaves extract and the result shown in Figure 2.

Chromatographic patterns for ethanolic extract were shown on track 2 to track 5, while the patterns for water extract were shown on track 6 to track 9. As shown in Figure 2, chromatographic patterns of all samples were separated well using toluene: ethyl acetate: formic acid in a 58: 33: 9 ratios. Futhermore, the spot of all samples were seen clearly under ultraviolet (UV) light at $245 \mathrm{~nm}$ and $366 \mathrm{~nm}$ after sprayed with aluminum chloride $\left(\mathrm{AlCl}_{3}\right) 1 \%\left(\% \mathrm{w} / \mathrm{v}\right.$ in ethanol) and sulfuric acid $\left(\mathrm{H}_{2} \mathrm{SO}_{4}\right) \quad 10 \%$ $(\% \mathrm{v} / \mathrm{v}$ in water). Based on Figure 2, the chromatographic pattern of all samples of ethanolic extract (track 2 to track 5) were shown almost have the same pattern. This also occurs in chromatographic patterns of water extract (track 6 to track 9). These results were indicated that the heat process in extraction process (track 3, 4, 5 for ethanolic extract and track $7,8,9$ for water extract) did not damage the compounds in extract.

Intermolecular attraction between the eluent and the compounds determine the solubility of the mobile phase. The polarity of the mobile phase was used in this experiment is semi polar. As shown in Figure 2, many secondary metabolites in ethanolic extract more attracted in the mobile phase, while the compounds in the water extract spends more time in adsorbent (polar). In addition, Figure 2 showed that many compunds as shown as spots more attracted with eluent than with adsorbent. It indicates that, many compounds in A. conyzoides L. leaves are semipolar.

As shown in Figure 2, the chromatographic patterns of ethanolic extract have same profile with the chromatographic pattern in water extract, especially spot at $R_{f} 0.51$ which marked by black circle spot. Moreover, the sample of sample extract at $\mathrm{R}_{\mathrm{f}} 0.51$ equal to the spot of standard quercetin. These results indicate that quercetin compounds have been extracted successfully from the leaves of A. conyzoides L. The identity

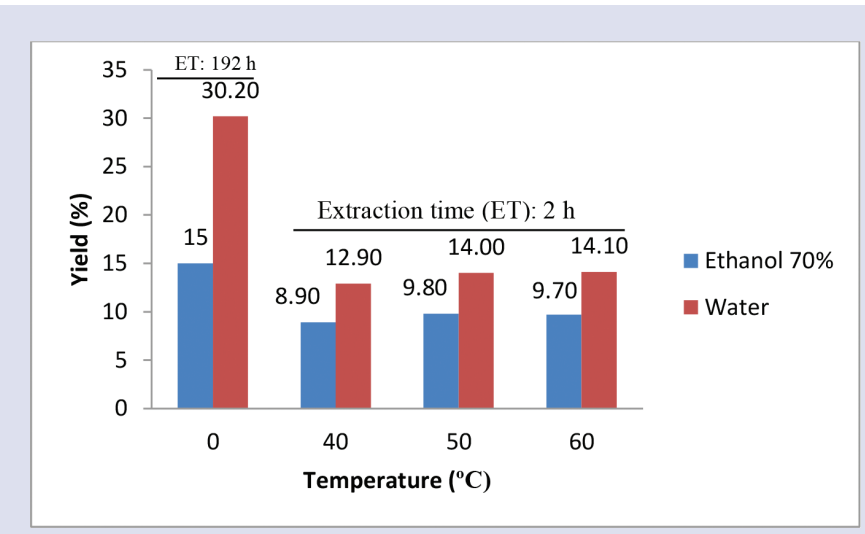

Figure 1: Effect solvent, extraction time, and temperature on total yield extract

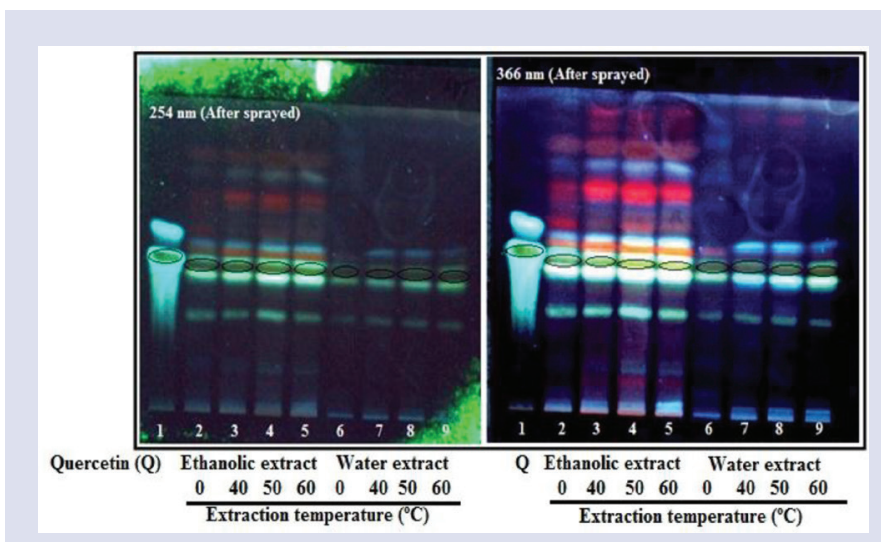

Figure 2: TLC profile of $A$. conyzoides L. leaves extract at 254 and $366 \mathrm{~nm}$ (after sprayed with aluminium chloride $1 \%$ and sulfuric acid 10\%) which obtained by different extraction methods. Extraction time in maceration technique $\left(0^{\circ} \mathrm{C}\right)$ is $192 \mathrm{~h}$, while extraction time in digestion technique is only $2 \mathrm{~h}$

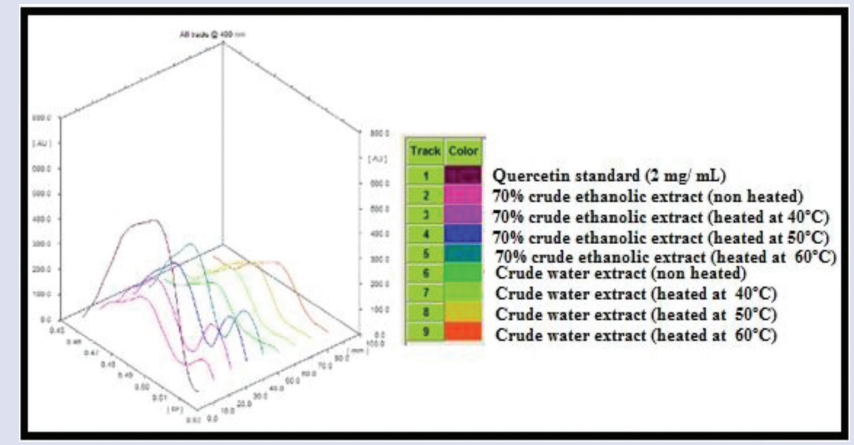

Figure 3: Spectra overlay of quercetin corresponding peak in all extracts of $A$. conyzoides $\mathrm{L}$.

of the quercetin spots in the sample was confirmed by comparing the UV-Vis absorbtion spectra between spectra of samples and standard using a CAMAG TLC Scanner 3 (Figure 3). 


\section{The effect of extraction conditions on total quercetin content}

The previous study reported that flavonoids and tannin content from the ethanolic extract of the leaves of Ageratum conyzoides L. has anti-inflammatory activity. ${ }^{19}$ Awad et al in 2013 reported that quercetin isolated from the mucilage of crude extract of A. conyzoides L. leaves has antiinflammatory activites against carrageenan induced edema. ${ }^{6}$ Therefore, the present study was used quercetin content to evaluate the influence of extraction conditions and also as a guide to choose a suitable extraction technique for A. conyzoides $\mathrm{L}$ which can produce high of quercetin content. The content of quercetin was determined using TLC densitometric method and the results are shown in Figure 4.

As shown in Figure 4, total quercetin in crude ethanol higher than in crude water. This may possible by by phenolic compounds including quercetin is more attracted in ethanol than in water. It may caused by interaction between hydrogen in phenol compounds and polarity of solvent. The increasing of carbon chain length of solvent will increase the solubility of hydrogen of phenols compouds in alcohol. ${ }^{20}$

Figure 4 was confirmed that temperature parameters varied in this study affected the quercetin content in A. conyzoides L. leaves extract. Figure 4 showed that, the quecetine content in the A. conyzoides L. leaves extract can enhanced with increasing temperature up to $60^{\circ} \mathrm{C}$ in various solvent, although the time of extraction is only $2 \mathrm{~h}$. Thus, these results indicated that the temperature during extraction process have influence against quercetin content. The increase in quercetin accumulation is may related to the Maillard reaction products which have responsibilty for the increase in quercetin content as a natural phenolic compound after heating. The Maillard reaction can liberate the cleaving of the esterified and glycosylated bond in phenolic compounds. ${ }^{21}$

Figure 4 showed that the longger extraction time only did not increase the quercetin content in the extract. Total quercetin content in sample extract which obtained from maceration technique lower than sample extract from digestion technique. For the example, total quercetin in ethanolic extract from maceration is $118.43 \mathrm{ppm}$, while total quercetins from ethanolic extract with digestion technique at $60^{\circ} \mathrm{C}$ can rich up to $209.62 \mathrm{ppm}$. It suggests that the heat extraction method shown to have advantages of savings in time and energy to extract the quercetin compounds in A. conyzoides L. leaves successfully.

\section{Evaluation the suitable method that impart a high level of total yield extract and quercetin content}

As described in Figure 1, the digestion techniques shown to have advantages of savings in time and energi, because this technique can produce a high total yield extract. Moreover, based on Figure 2, the digestion technique did not damage the compounds in extract. Futhermore, Figure 4 showed that the optimal total quercetin content (209.622 ppm) has obtained by digestion technique for two hours at $60^{\circ} \mathrm{C}$ using ethanol as a solvent. Based on these results, it suggest the digestion technique for two hours at $60^{\circ} \mathrm{C}$ using ethanol as a solvent is the most efficient method to obtain the highest total yield extract and quercetin content in A. conyzoides $\mathrm{L}$. leaves. Thus, this method will be used for futher study to evaluate the chemical profile of $A$. conyzoides L. leaves.

Application of TLC in analysis of phytochemical profiling of plant extract A phytochemical profiling of an herbal medicine (HM) is a chromatographic pattern of the extract of some common chemical components of pharmacologically active and or chemical characteristics. ${ }^{22}$ This chromatographic profile is an important step for the establishment of a consistent biological activity, a consintent chemical profile, or simply a quality assurance program for production and manufacturing of herbal drug. ${ }^{23}$ Because of these parameters are crucial for preparation of accurate and potent, this work attempts to quantification of the biomarkers and/ or chemical markers and and also to investigate chromatographic phytochemicals profiles of $A$. conyzoides L. leaves extract. The phytochemicals profiling are shown in Figure 5.

In the current study, a phytochemicals profiling of $A$. conyzoides $\mathrm{L}$. leaves exract were identified from three different origin of plant, there are Materia Medica from East Java, Balitro from West Java, and Purwokerto from Central Java. All of the areas of origin of plant are still in place in Indonesia country. The purpose of collecting plant in various areas is to collect the representative samples, so the phytochemicals profile which obtained from this experiment can demonstrate the profile of $70 \%$ ethanolic A. conyzoides L. leaves extract from all of area, especially in Indonesia. The extraction method in this study uses a digestion technique at $60^{\circ} \mathrm{C}$ for $2 \mathrm{~h}$ and uses an ethanol as a solvent.

TLC profiles were shown in Figure 5 indicate that all sample consitituent were clearly separated without any tailing and diffuseness and showed that all of sample extracts have the same profiles. Based on TLC profiles, there are many spots with different $R_{f}$ values and the various of $R_{f}$ values describe the presence of number of phytochemicals constituent in A. conyzoides $\mathrm{L}$. leaves extract. The results showed that there are four the major spots can be seen clearly at $366 \mathrm{~nm}$, among others M1, M2, M3, and M4. All of these spots can be used as a marker or as stability indicating methods for the determination of raw material or pharmaceutical formulations of A. conyzoides L. leaves extract. ${ }^{24}$

As previously explained, quercetin became as a marker compound of A. conyzoides L. leaves extract on this study because of many previous study has releaved the activity of quercetin from this plant. Marker compound means is a chemical constituent within a medicinal that can be used to verify its potency or identity. It is verry difficult to identify correct marker compounds for all traditional medicinal, but using chromatographic fingerprint, the authencation and identification of herbal medicines can be accurately conducted..$^{25}$ Therefore, the use of markers and chromatographic fingerprinting techniques can give useful information assisting manufacturing control, minimising variations in production batches and assuring batch to bacth consistency, with reproducible results. ${ }^{26}$

As shown in Figure 5, TLC profiles showed that the $\mathrm{R}_{\mathrm{f}}$ value of all samples extract at 0.51 (M2) equal to the standard quercetin. It revealed the presence of quercetin in the sample extract. This result was confirmed by overlaying their UV absorbtion spectra with the reference standard as quercetin and scanned at $400 \mathrm{~nm}$ using a CAMAG TLC Scanner 3 integrated with winCATS software and the results shown in Figure 6.

Estimation of quercetin in $70 \%$ ethanolic leaves extract of $A$. conyzoides L. using TLC-densitometric method

Phytochemical profiles of plant extract are not adequate enough to ensure the quality of plant. Based on WHO guidelines in 2011 for the Quality Controls Methods for Herbal Medicine, there is a need quantitative analysis to ensuring the bioactive marker which has a responsible with therapeutic activity, so the activity of the extracts is consistent and reproducible in each product. ${ }^{27}$ Therefore, this research also intended to evaluate the total quercetin in each of sample extract and the results were shown in Table 1.

The results in Table 1 showed that the different location of plant can caused the different concentration of quercetin content. The ethanolic extracts from the leaves collected from Balitro exhibited the highest level of quercetin content ( $54.9165 \mathrm{ppm}$ ) followed by Materia Medica (52.7134) and Purwokerto (40.7134). However, the differentiation of the results is not too far. The quercetin content in each sample were measured by a graph was plotted taking concentration on $\mathrm{X}$ axis and absorbance on $\mathrm{Y}$ axis using standard quercetin (0 to $120 \mathrm{ppm}$ ). The linear correlation data of standard quercetin can see in Figure 7. 


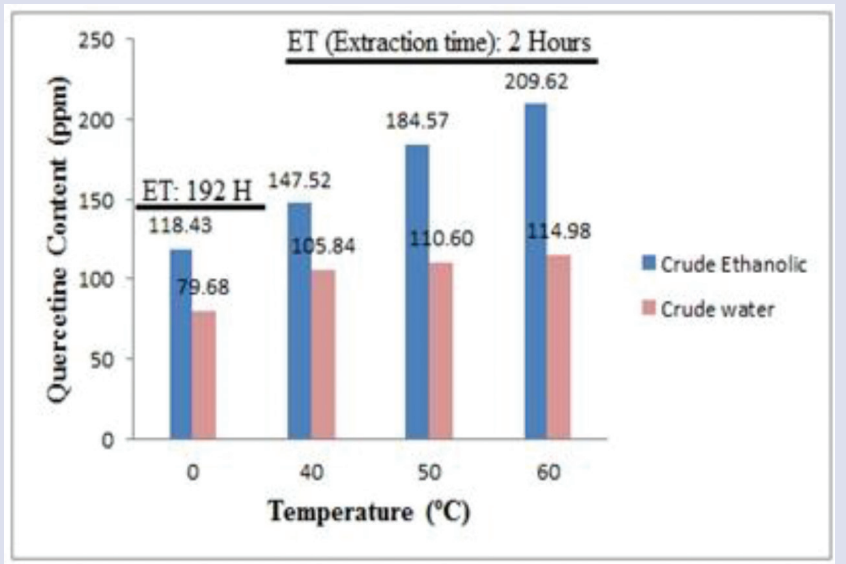

Figure 4: Estimation of the quercetin content from crude extract of A. conyzoides $L$. leaves

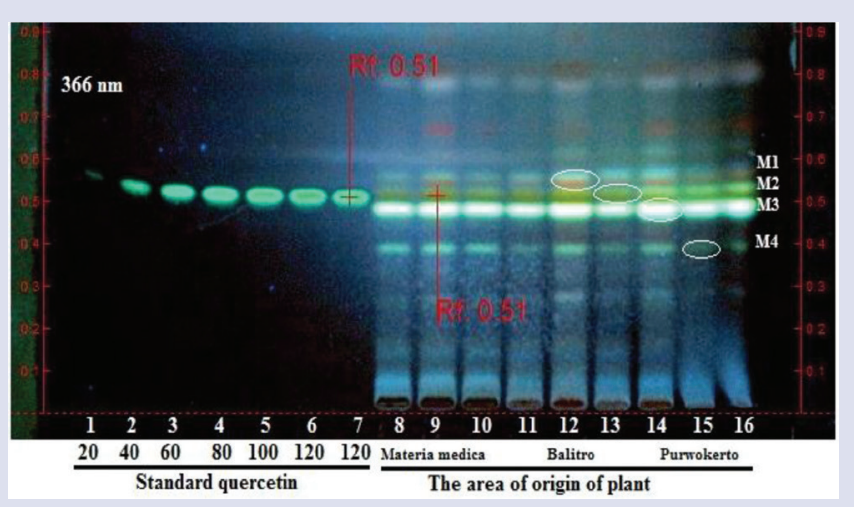

Figure 5: Phytochemical profiles of $70 \%$ ethanolic leaves extract of A. conyzoides $\mathrm{L}$. leaves from various the area of origin of plant

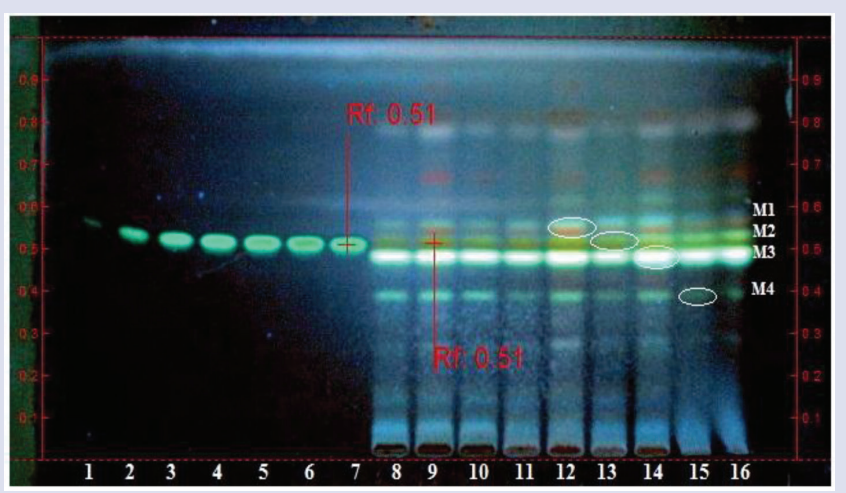

Figure 6: TLC-densitometry chromatogram for $70 \%$ ethanolic leaves extract of $A$, conyzoides $\mathrm{L}$. from several of origin of plant: $\mathrm{A}$. The plant's source was came from Materia medica (East Java); B. The plant's source came from Balitro (West Java); and C. The plant's source was came from Purwokerto (Central Java).
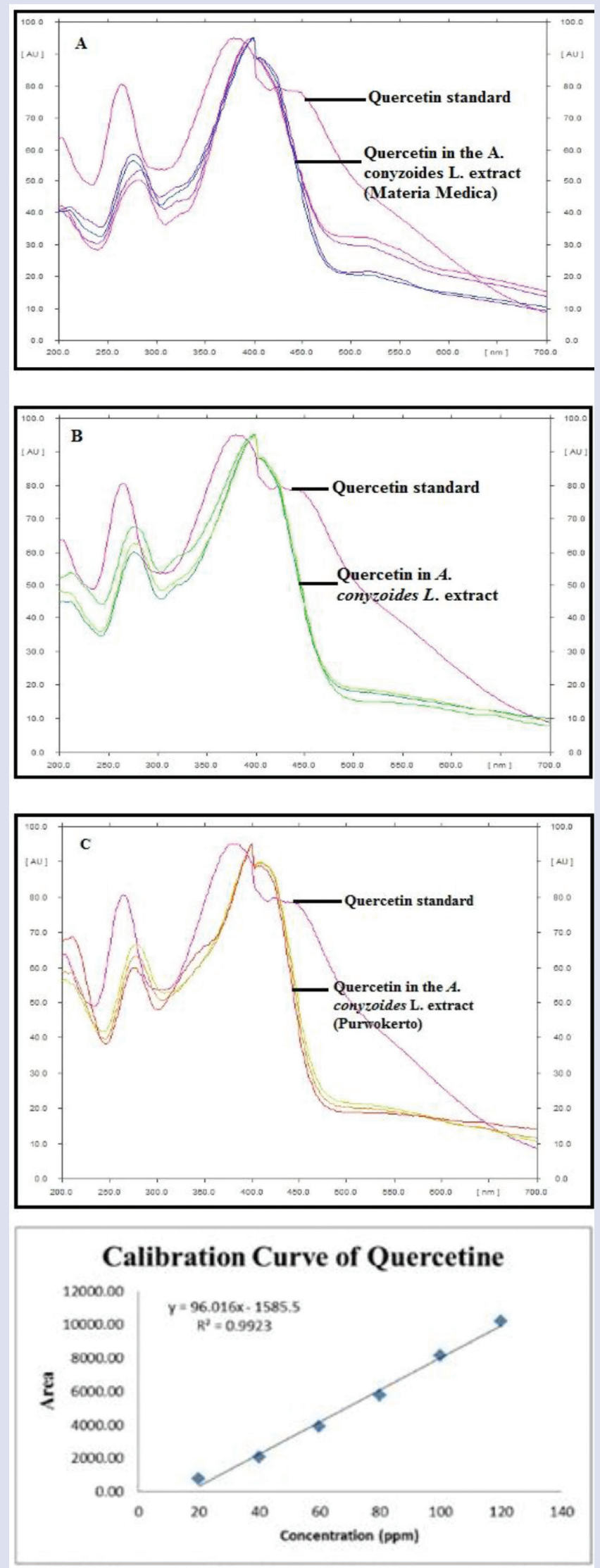

Figure 7: The calibration curve of standard quercetin 


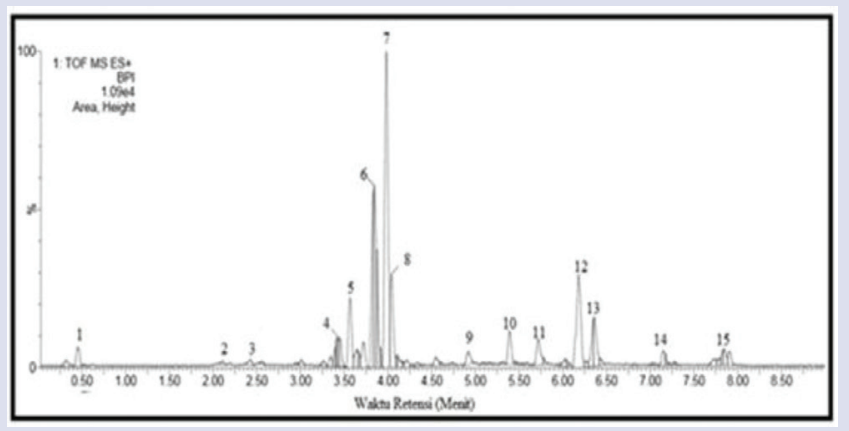

Figure 8: LC-MS Chromatogram of 70\% ethanolic leaves extract of A. conyzoides $\mathrm{L}$.

Table 1: Estimation of quercetin content in $70 \%$ ethanolic leaves of A. conyzoides $L$

\begin{tabular}{ccc}
\hline Source of Plant & Quercetin content (ppm) & \%RSD \\
\hline Purwokerto & 40.7134 & 1.88 \\
Balitro & 54.9165 & 3.91 \\
Materia Medica & 52.7134 & 2.23 \\
\hline
\end{tabular}

The quercetin content in Table 1 was determined from three experiments in on day (for intra-day precision) which are reported as \%RSD. The intra-day precision as shown in Table 1 ranged from 1.88 to 3.91 . According to the AOAC, the results demonstrate acceptable repeatibility because the \%RSD value did not exceed 5\%. ${ }^{28}$ Moreover, the linear regression equation as shown in Figure 8 was found to be $Y=96.016 x$ - 1585.5 with correlation coefficient (r) 0.9923 . The correlation coefficient was used as an indicator of linearity. Because of the correlation coeffisient of this result high than 0.99 , it indicates that the calibration curve of standard quercetin has a high linearity relationship between area and concentration of standard quercetin. ${ }^{29}$

\section{Application of LC-MS in analysis of phytochemical profiling of plant extract}

Liquid chromatography separation the component of $70 \%$ ethanolic leaves extract of $A$. conyzoides L. was examined on Aquity UPLC BEH C18 colomn and the LC-MS chromatogram was shown in Figure 8. Tentative identification of phytochemical in samples extract was shown in Table 2.

As shown in Figure 8, a total of 11 compounds were identified by comparing molecular weight $(\mathrm{M})$ and $\mathrm{m} / \mathrm{z}$ fragment with the literature data and the results were shown in Table 2. The results of the LC-MS analysis provide 15 major peaks determining the presence of phytochemical compounds, but only 11 compounds were identified. The results in Table 2 showed that ethanolic leaves extract of $A$. conyzoides L. has higher flavonoid content and the one of peak was identified as quercetin. As shown in Figure 8, quercetin was not a major component in $70 \%$ ethanolic extract of $A$. conyzoides L. leaves. The major component in the sample extract is kaempferol-7-O-rhamnopyranoside. This compound can be used as a chemical marker same as with quercetin.

\section{Determination of the yield extract of $70 \%$ ethanolic leaves extract of $A$. conyzoides $L$.}

Based on previous result, digestion method at $60^{\circ} \mathrm{C}$ for $2 \mathrm{~h}$ using ethanol $70 \%$ as solvent is an effective method for the extraction of $A$. conyzoides $L$. leaves. Therefore, this method was used in this current study and the method were replicated in extraction process of plant from various location to obtain the standar of yield extract of $70 \%$ ethanolic leaves extract of $A$. conyzoides $\mathrm{L}$. The results were described in Table 3.

As can be seen from the results in Table 3, a highest of yield extract was obtained from Materia Medica $(16.60 \% \mathrm{w} / \mathrm{w})$, followed by Balitro $(15.75 \% \mathrm{w} / \mathrm{w})$ and Purwokerto $(14.15 \% \mathrm{w} / \mathrm{w})$. Based on these results, the range of standard of yield extract is 14.15 to $16.60 \% \mathrm{w} / \mathrm{w}$. This result can be used as one of the parameters standards to development standardizes extract.

Table 2: Phytochemical constituent in $70 \%$ ethanolic leaves extract of $A$. conyzoides L. by LC-MS

\begin{tabular}{|c|c|c|c|c|c|}
\hline Peak Number & $T_{R}$ (minutes) & M & $\mathrm{m} / \mathrm{z}$ Fragment & Tentatif Identification & Literature \\
\hline 1 & 0.454 & 301 & 620,302 & Quercetin-3-O-glycoside & (30) \\
\hline 2 & 2.111 & 343 & 366,344 & Hyperoside & (31) \\
\hline 3 & 2.422 & 348 & 412,349 & Unidentified & - \\
\hline 4 & 3.456 & 388 & 421,389 & Monohydroxy-penta-methoxy-flavone & (32) \\
\hline 5 & 3.563 & 418 & 441,419 & Kaempferol-3-O-pentose & (33) \\
\hline 6 & 3.828 & 402 & 425,403 & Hexa- methoxy flavone & (32) \\
\hline 7 & 3.980 & 432 & 455,433 & Kaempferol-7-O-rhamnopyranoside & (31) \\
\hline 8 & 4.046 & 416 & 434,417 & Eupalestin & (34) \\
\hline 9 & 4.966 & 216 & 313,218 & Luteoline & (35) \\
\hline 10 & 5.388 & 720 & 721,369 & Unidentified & - \\
\hline 11 & 5.767 & 608 & 609,324 & Quercetin-3-O-rutinoside & (36) \\
\hline 12 & 6.168 & 337 & 414,338 & Luteolin-7-O-glucuronide & (31) \\
\hline 13 & 6.383 & 440 & 482,441 & Apigenin & (31) \\
\hline 14 & 7.152 & 663 & 708,664 & Unidentified & - \\
\hline 15 & 7.868 & 509 & $554,510,170$ & Unidentified & - \\
\hline
\end{tabular}


Tambunan et al:: New method to increase high yield of quercetin by short time

Table 3: The yield extract of $70 \%$ ethanolic leaves extract of $A$. conyzoides $L$. with various of origin of plant

\begin{tabular}{cc}
\hline Origin of Plant & Yield extract $(\% w / w)$ \\
\hline Materia Medica (East Java) & $16.60 \pm 0.1000$ \\
Balitro (West Java) & $15.75 \pm 0.2500$ \\
Purwokerto (Central Java) & $14.15 \pm 0.0500$ \\
\hline
\end{tabular}

The methods for standardizing different batches for long Term from A. conyzoides $L$. leaves

As the explanation before, the natural product was influenced by many factors. Thus, the biggest challenge in the production of herbal medicines is obtained the quality, efficacy, and safety from herbal product and it should be reproducible. Therefore, there is need a tool to standardize the natural product from different bathes. According t the WHO guideline, there are many parameters should be checked to Development the standardize extract such as physicochemical parametes (yield extract, loss on drying, total ash value, etc), quantitative of bio-active marker, chromatographic pattern, etc. Based on the previous study, the range of standard of yield extract is 14.15 to $16.60 \% \mathrm{w} / \mathrm{w}$, while the range of quercetin content is $40.71 \mathrm{ppm}$ to $52.71 \mathrm{ppm}$. Based on TLC profile, there are four major spot (M1, M2, M3, and M4), while based on LC-MS profile, quercetin and kaempferol can be used as marker compounds. All of these results can be used to identify proper quality of $A$. conyzoides L. leaves or can be used as a guideline for development of the standardize extract.

\section{CONCLUSIONS}

The parameters of extraction process have an influence in the performance of the extraction process. However, our results suggest that the digestion technique for two hours at $60^{\circ} \mathrm{C}$ using ethanol as a solvent is the most efficient method to obtain the highest total yield extract and quercetin content in A. conyzoides L. leaves. The range of standard of yield extract and quercetin content in sample extract which combined by TLC and LC-MS profiles can be used to determine the proper quality of A. conyzoides $\mathrm{L}$. leaves in different batches of herbs for long term.

\section{ACKNOWLEDGEMENT}

This research work was supported by Dexa laboratories of Biomolecular Sciences (DLBS), Cikarang, Bekasi, Indonesia. The author would like to aknowledgment, Dr. James Sinambela as Research Manager of a DLBS for the patient, guidance, encouragement, and for the advice which he has provide to me throughout my time at DLBS. The authors would also like to thank to Mrs. Ujiatmi, Mr. Laurentius, Mr. Irfan, and all the members of DLBS who helped and support me, and also for the friendship during completing this work at DLBS.

\section{CONFLICT OF INTEREST}

We declare that we have no conflict of interest.

\section{ABBREVIATION USED}

A. conyzoides L.: Ageratum conyzoides Linn.; TLC: Thin Layer Chromatography; LC-MS: Liquid Chromatography-Mass Spectroscopy; DLBS: Dexa Laboratories of Biomolecular Sciences; UV-Vis: Ultraviolet-Visible; HM: Herbal Medicine; M1: Marker 1; M2: Marker 2; M3: Marker 3; M4: Marker 4; RSD: (Relative Standard Deviation); UPLC: Ultra Performace Liquid Chromatography; qTOF-MS: Quadropole Time-of-Flight Mass Spectrometer; ESI: Electrospray Ionization; v/v: volume/volume; $\mu \mathrm{m}$ : mikro meter.

\section{REFERENCES}

1. Bahtiar A, Nurazizah M, Roselina T, Tambunan AP, Arsianti A. Ethanolic extracts of babandotan leaves (Ageratum conyzoides L.) prevents inflammation and proteoglycan degradation by inhibiting TNF- $\alpha$ and MMP-9 on osteoarthritis rats induced by monosodium iodoacetate. Asian Pacific Journal of Tropical Medicine. 2017;10(3):270-7.

2. Kaur R, Kaur S. Anxiolytic potential of methanol extract from Ageratum conyzoides Linn Leaves. PHCOG J. 2015;7(4):236-41.

3. Shailajan S, Wadke P, Joshi H, Tiwari B. Evaluation of quality and efficacy of an ethno-medicinal plant Ageratum conyzoides L. in the management of pediculosis. Journal of Young Pharmacists. 2013;5(4):139-43.

4. Ola-Davies OE, Akinrinde AS. Acute sodium Arsenite-induced hematological and biochemical changes in wistar rats: Protective effects of ethanol extract of Ageratum conyzoides. Pharmacognosy research. 2016;8(Suppl 1):S26.

5. Okunade AL. Ageratum conyzoides L.(Asteraceae). Fitoterapia. 2002;73(1):1-6.

6. Awad NE, Kassem HA, Matloub AA, Elkhyat Z, Elfeky AM. Anti-inflammatory Evaluation of Ageratum conyzoides L. Leaves. Planta Medica. 2011;77(12):PF69.

7. Vyas J, Itankar P, Tauqeer M, Kelkar A, Agrawal M. Development of HPTLC method for estimation of piperine, guggulsterone $\mathrm{E}$ and $\mathrm{Z}$ in polyherbal formulation. Pharmacognosy Journal. 2013;5(6):259-64.

8. Martins FS, da Conceição EC. Evaluation of extraction method on the chemical composition in Apeiba tibourbou Aubl's extracts. Pharmacognosy magazine. 2015;11(42):368.

9. Sarhadynejad Z, Pardakhyty A, Mandegary A, Afsharypuor S, Sharififar F. Physicochemical characterization, standardization and in vitro determination of radical scavenging activity of Zereshk-e-Saghir, a traditional preparation, and its ingredients. Journal of Young Pharmacist. 2017;9(2): 224-9.

10. Owis Al, El-Naggar EMB. Identification and quantification of the major constituents in Egyptian carob extract by liquid chromatography-electrospray ionization-tandem mass spectrometry. Phcog Mag [serial online] 2016 [cited 2017 Jun 11];12, Suppl S1:1-6. Available from: http://www.phcog.com/text. asp?2016/12/45/1/176108

11. Jones WP, Kinghorn AD. Extraction of plant secondary metabolites. 2nd Ed. Sarker SD, Latif Z, Gray Al, Editors. Totowa: Humana Press Inc. 2012.

12. Nguyen VT, Scarlett CJ. Mass Proportion, Bioactive Compounds and Antioxidant Capacity of Carrot Peel as Affected by Various Solvents. Technologies. 2016;4(4):36.

13. Kaulmann A, Bohn T. Bioactivity of Polyphenols: Preventive and Adjuvant Strategies toward Reducing Inflammatory Bowel Diseases-Promises, Perspectives, and Pitfalls. Oxidative medicine and cellular longevity. 2016.

14. Chavan UD, Amarowicz R. Effect of various solvent systems on extraction of phenolics, tannins, and sugars from Beach Pea (Lathyrus matitimus L.). International Food Research Journal. 2013; 20(3):1139-44.

15. Pham HN, Nguyen VT, Vuong QV, Bowyer MC, Scarlett CJ. Effect of extraction solvents and drying methods on the physicochemical and antioxidant properties of Helicteres hirsuta Lour. Leaves. Technologies. 2015;3(4):285-301.

16. Abdelfadel MM, Khalaf HH, Sharoba AM, Assous M. Effect of extraction methods on antioxidant and antimicrobial activities of some species and herbs extracts. Journal of Food Technology and Nutritional Sciences. 2016;1(1):1-14.

17. Azmir J, Zaidul IS, Rahman MM, Sharif KM, Mohamed A, et al. Techniques for extraction of bioactive compounds from plant materials: a review. Journal of Food Engineering. 2013;117(4):426-36

18. Kamboj A. Analytical evaluation of herbal drugs, drug discovery research in pharmacognosy. In: Vallisuta O, editor. Croatia: Intech Open Access Publisher. 2012

19. Hassan MM, Shahid-Ud-Daula AF, Jahan IA, Nimmi I, Adnan T, et al. Anti-inflammatory Activity, Total Flavonoids and Tannin Content from the Ethanolic Extract of Ageratum conyzoides Linn. Leaf. International Journal of Pharmaceutical and Phytopharmacological Research. 2017;1(5):234-41.

20. Feng G, Liu Z, Chen P, Lou H. Influence of solvent on upgrading of phenolic compounds in pyrolysis bio-oil. RSC Advances. 2014;4(91):49924-9.

21. Maillard MN, Soum MH, Boivin P, Berset C. Antioxidant activity of barley and malt: relationship with phenolic content. LWT-Food Science and Technology. 1996;29(3):238-44.

22. Nikam PH, Kareparamban J, Jadhav A, Kadam V. Future trends in standardization of herbal drugs. Journal of Applied Pharmaceutical Science. 2012;2(6):33-44.

23. Bajpaj R, Jain N, Pathak AK. Standardization of ethanolic extract of Cucurbita maxima Seed. Journal of Applied Pharmaceutical Science. 2012;2(8):92-5.

24. Folashade O, Omoregie H, Ochogu P. Standardization of herbal medicines-A review. International Journal of Biodiversity and Conservation. 2012;4(3):101-12.

25. Chothani DL, Patel MB, Mishra SH. HPTLC fingerprint profile and isolation of marker compound of Ruellia tuberosa. Chromatograhy Research International. 2012;1-6.

26. Pattanayak P, Mohapatra P, Jena RK, Panda SK. Standardization of Sulaharan yoga: An ayurvedic tablet formulation. Indian Journal of Pharmaceutical Sciences. 2011;73(1):65-70.

27. Organization WH. Quality controls methods for herbal medicines Switzerland: WHO Press; 2011. 
28. (AOAC) AOAC. Guidelines for Single Laboratory Validation of Chemical Method for Dietary Supplements. U.S.A: Maryland. 2002.

29. (UNODC) UNODC. Guidance for the validation of analytical methodology and calibration of equipment used for testing of Illicit drugs in seized materials and biological specimens. New York: United Nations Publication. 2009.

30. Gates PJ, Lopes NP. Characterization of Flavonoid Aglycones by Negative Ion Chip-Based Nanospray Tandem Mass Spectrometry. International journal of analytical chemistry. 2012:1-8.

31. Ibrahim RM, El-Halawany AM, Saleh DO, El Naggar EM, El-Shabrawy AE et al. HPLC-DAD-MS/MS profiling of phenolics from Securigera securidaca flowers and its anti-hyperglycemic and anti-hyperlipidemic activities. Revista Brasileira de Farmacognosia. 2015;25(2):134-41.

32. Zhang J, Li Y, Chen SS, Zhang L, Wang J, et al. Systems pharmacology dissection of the anti-inflammatory mechanism for the medicinal herb Folium eriobotryae. International journal of molecular sciences. 2015;16(2):2913-41.

33. Simirgiotis MJ. Antioxidant capacity and HPLC-DAD-MS profiling of Chilean
Peumo (Cryptocarya alba) fruits and comparison with German Peumo (Crataegus monogyna) from Southern Chile. Molecules. 2013 ;18(2):2061-80.

34. Faqueti LG, Brieudes $V$, Halabalaki M, Skaltsounis AL, Nascimento LF, et al. Antinociceptive and anti-inflammatory activities of standardized extract of polymethoxyflavones from Ageratum conyzoides. Journal of ethnopharmacology. 2016;194:369-77.

35. Plazonic A, Bucar F, Maleš Ž, Mornar A, Nigovic B, et al. Identification and quantification of flavonoids and phenolic acids in burr parsley (Caucalis platycarpos L.), using high-performance liquid chromatography with diode array detection and electrospray ionization mass spectrometry. Molecules. 2009;14(7):2466-90.

36. Alberti Á. LC-ESI-MS/MS methods in profiling of flavonoid glycosides and phenolic acids in traditional medicinal plants: Sempervivum tectorum L. and Corylus avellana L (Doctoral dissertation). 2014.

37. Sreedhar S, Kumar UP, Girija TP, Remashree AB. Pharmacognostic standardisation of Combretum albidum G. Don leaf; a medicinally important liana. Pharmacognosy Journal. 2013;5(6):247-55

\section{ABOUT AUTHORS}

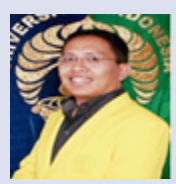

Anton Bahtiar obtained his Ph. D. degree in 2010 from Nara Institute of Science and Technology, Japan. Currently, $\mathrm{He}$ is lecturer and researcher at faculty of pharmacy, University of Indonesia since 1998. He is also a head of Pharmacology and Toxicology Laboratory. His research projects are focus on Herbal medicine, and tried to solve the mechanism of action of herbal medicine, especially for osteoporosis and menopouse.

\section{SUMMARY}

- Digestion technique at $60^{\circ} \mathrm{C}$ can produce an extract with high yield extract and high of total quercetin.

- The solvent composition had an influence on TLC profile of $A$. conzyoides $L$. leaves extract, but the time and temperature of extraction have not.

- Based on TLC-densitometric quantification, total quercetin in crude ethanol higher than in crude water.

- Based on LC-MS profile, Kaempferol-7-O-rhamnopyranoside is the major component in the extract. In addition to Kaempherol-7-O-rhamnopyranoside, quercetin was also identified on LC-MS profile.

- The range of quercetin content in the leaves extract of $A$. conyzoides $L$. which combined with TLC and LC-MS profile can be used to determine the proper quality of plant material of $A$. conyzoides $L$. leaves.

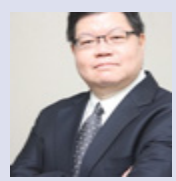

Raymond R. Tjandrawinata obtained his Ph.D degree in 1994 from Department of Medicine, University of California, San Francisco (UCSF), California. Currently, He is an Executive Director at Dexa Laboratories of Biomolecular Sciences (DLBS), Director of Innovation and Scientific Development, and Director of Corporate Development at DexaMedica. He is also teaching at the university level in the capacity of an adjunct faculty member at the School of Biotechnology at Atma Jaya University.

Cite this article: Tambunan AP, Bahtiar A, Tjandrawinata RR. Influence of Extraction Parameters on the Yield, Phytochemical, TLC-Densitometric Quantification of Quercetin, and LC-MS Profile, and how to Standardize Different Batches for Long Term from Ageratum conyoides L. Leaves. Pharmacog J. 2017;9(6):767-74. 